\title{
Teachers' Perceptions of Practices and Challenges of Innovating for the Inclusion of Special Needs University English Language Learners in Oman
}

\author{
Saleh Al-Busaidi* Victoria Tuzlukova \\ Sultan Qaboos University, Sultanate of Oman
}

Received: 31/10/2017 Accepted: 6/2/2018

\begin{abstract}
This study explored how English language teachers at Sultan Qaboos University's Center for Preparatory Studies in Oman perceive practices and challenges related to inclusive education and innovating in teaching English to visually impaired students. The study was carried out taking descriptive qualitative approach. Interviews with seven English language teachers were used to collect data. We asked them about both successful and challenging aspects of creating an inclusive language learning environment and using assistive technologies. We found that assistive technology is crucial to language learning of special needs students. The identified challenges include insufficient teachers' knowledge and expertise in inclusive education, lack of institutional focus of attention on systematic planning and material design for inclusion, novelty of the concepts of inclusive education and assistive technology among others. The results of the study indicate the need for targeted teacher training and professional development, and suggest that innovations in education and technology can be effectively used to shift practices and perspectives of English language teaching in the context of Oman to being universally accessible, equally usable, more inclusive and tailored to students' individual needs.
\end{abstract}

Keywords: Innovations in education, visually impaired students, language learning, Sultan Qaboos University.

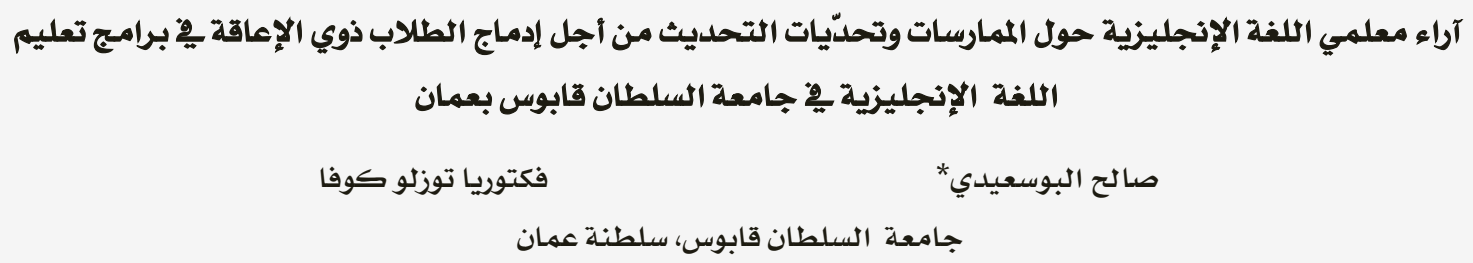


Transformation of tertiary education systems towards a more inclusive direction requires generating knowledge relevant for the context and needs. However, to date, there has been little research and discussion in the literature of the particular concerns and best practices related to the inclusion of special needs students.

The idea of "teaching students with disabilities in their neighborhood school within the regular classroom with their peers without disabilities" (Rafferty, Boettcher, \& Griffin, 2001, p. 266), or inclusive education, has just recently received attention and support across the globe as an educational idea and movement in education. Seeing inclusive education as a major step towards acknowledging diversity and equal access to education for all, many governments and educational institutions made commitments to inclusive education and have been engaged in systematic reforms emphasizing it (Rafferty, Boettcher, \& Griffin, 2001). Consequently, legislations and systems that make it possible for students with disabilities to attend schools alongside other students in the same classroom have been introduced. The first international effort was the Salamanca Statement issued at the World Conference on Special Needs Education: Access and Quality, held in Salamanca, Spain, June 1994, where more than 300 participants from 92 governments and 25 international organizations deliberated the need for educational reform to promote the idea of inclusive education. Another example is United Nations' Convention on the Rights of Persons with Disabilities in 2006, which is an international human rights treaty intended to protect the rights of people with disabilities. The treaty has been signed by many states.

The inclusive education movement has helped in giving students with different disabilities in many countries a fair and equal chance to quality education, except in a few cases of severe mental disorders where inclusion is not deemed possible or beneficial. There have been many successful cases of inclusive programs in many countries due to the longstanding policies, commitment and actions aimed at redesigning and restructuring of general education classrooms so that they more closely resembled special education: low student-tostaff ratio, intensive and prescribed basic skills instruction, performance monitoring, and the opportunity for intensive, one-to-one instruction (Manset \& Semmel, 2016), and effective integration of components appropriate to technology-based learning environments (Permvattana, Armstrong \& Murray, 2013). However, this is not necessarily the same in other parts of the world where teaching students with disabilities together with regular students is still rather new. This applies to most of the countries in the Arabian Gulf, and indeed to the Sultanate of Oman.

The purpose of this study is to explore teachers' perceptions of practices and challenges of innovating for the inclusion of special needs university English language learners in Oman. In more detail, it focuses on the successful and challenging aspects of inclusion into a language learning environment of students who have significant loss of vision.

\section{Inclusive language education as a movement in education}

Inclusive education where students with and without disabilities learn together in the same classroom is one of the greatest and very recent innovations in language education. The effects of innovations on effective language learning, students' skill enhancement and personal development have been examined in multiple publications (Dudeney \& Hockly, 2012). Richard Hock (2015) in his review of the "Innovations in the continuing professional development of English language teachers" contends that "In a time when quality of teaching has been found to most influence learner achievement, there have been huge efforts to not only improve teaching, but to understand and share examples and developments in practice around the world" (p. 7). He further goes on to explain that, "Teachers and stakeholders involved in education strive to develop in the field of education, yet there's still the challenge of how to access valuable insights into ways to assist teachers to learn, share and network within themselves from areas all around the world" (p. 7).

Many definitions of the term innovation commonly explain it as the introduction of something new, a new idea, method, or device (Meriam Webster Dictionary, 2017). According to Milrood (2004), innovation can be defined as "the development and implementation of new ideas by people who over time engage in transactions with others within certain institu- 
tions in order to achieve change in beliefs, practices and products" (p. 5). In Klein and Knight's (2005) view, innovation is "a product or practice that is new to its developers and/or to its potential users" (p. 243). Innovation is also described as "a significant positive change" (The best definition of innovation, 2013 , n.p.). One element that has been woven into the definition of innovation over the time is that innovation is a change that is contextspecific (Hock, 2015, p.8). For example, in the field of language education, recent research indicates that applying technology in new ways can promote innovation, a culture of inquiry, creative exploration and independent learning, and enhance students' academic success (Alirezaeian, Chegini \& Farjad, 2015). However, in addition to technology, there are other multiple innovations that can promote successful learning. In Hock's (2015) view, the term "innovate" can be "quite elusive and quite difficult to define. Making changes in something established, especially by introducing new methods, ideas, or products is to innovate, yet what constitutes innovation is not necessarily a huge change, but could easily be some kind of small incremental changes to something that is established in that context" (p. 8).

The concept of inclusive education emerged in practice in the early 1990s. Prior to this period, it was believed that students with disabilities had learning difficulties that prevented them from learning. When such students were allowed to attend schools they had their own schools that in many cases served more as residential facilities than true learning institutions (Torreno, 2012). This practice of segregation was based on the assumption that such students needed special attention and therefore could not possibly be allowed to co-exist with other students in the same school. This misconception has started to fade away with the introduction of inclusive education and the increasing evidence about its short and long term benefits for students.

The concept of inclusion is based on the principle that children have different learning needs and abilities and that educational institutions need to innovate and adapt their structure, policies and practices in order to accommodate those needs (Sharma, Loreman \& Forlin, 2012). Education institutions need to re- spect individual differences and build programs that focus on learners' personal strengths rather than weaknesses (Meijer, 2010). Inclusive education is seen as a means to reform education in a way that welcomes diversity and combats social exclusion (Ainscow, 2005).

Many steps are needed in order to transform educational systems towards a more inclusive direction. One of the main steps in transforming education to become inclusive is changing systems and people's thinking and belief system. Ainscow (1999 and 2005) talks about what he calls 'levers for change' in his proposed framework (see Figure 1). The framework places school as the center for change. It emphasizes the development of schools into systems that welcome diversity and rejects social discrimination. Ainscow (2005) argues that the more enduring and high leverage efforts are the ones targeting developments within the school system. This is because what matters the most is not simply providing "inclusive and equitable education ... as a matter of access or act of accomplishment or completion" but rather "as an ongoing process" that has to be routinely evaluated (Evans, 2017, p. 40). The framework also emphasizes the role of external factors such as the community, education department, and forms of evaluation in building an inclusive system.

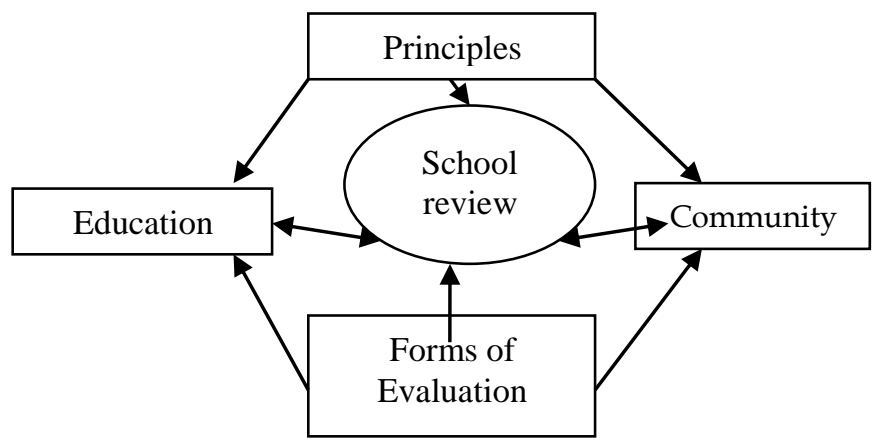

Figure 1: Levers for change (Ainscow, 2005)

The adoption of inclusive education inevitably requires the reconceptualization of education and change to the belief system and instructional practices. To achieve this, Ainscow argues, the focus should be on the ones with what he calls 'high leverage'. Such actions will have more enduring effects and will help change the behavior and attitudes of organizations and individuals towards inclusive schooling and develop schools that can ac- 
commodate the needs of the diverse range of learners. Actions should therefore focus on developing the school system as a whole taking into consideration all stakeholders rather than simply focusing efforts on integrating the disabled students into an existing system. This involves restructuring the mainstream educational system to accommodate the needs of every child regardless of ability or disability.

Within the school community, inclusive education requires the involvement and collaboration of all educators. Being an integral part of the learning process, teachers especially are at the forefront of inclusive education. They are the ones who interact the most with the learners and know about their challenges. The teachers' attitudes are therefore crucial in providing equitable and quality educational opportunities for students. Their attitudes towards inclusion have been reported to depend on the nature of the disability (Hwang \& Evans, 2011; Synder, 1999). Another factor that can affect their attitudes is the quality of resources and support available (Lindsay, 2007). Yet, teachers are more likely to express favorable views towards integration where inclusion is legally bound (Bowman, 1986).

One of the insights that can support inclusion of students with disabilities into the mainstream classroom, as well as develop their independent learning, is assistive technology. It is considered one of the most recent innovations in learning and teaching. Assistive technology is a broad term referring to any assistive, adaptive, and rehabilitative object or system used for the purpose of increasing or maintaining the capabilities of people with disabilities (U.S. Department of Health and Human Services Administration on Aging, 2003). Examples of assistive technologies include aids for daily living such as modified eating utensils, dressing aids, adapted personal hygiene aids, pencil holders, page turners and adapted books. They also include sensory aids for vision/hearing impaired such as magnifiers, large print screens, hearing aids, visual alerting systems, Braille and speech/telecommunication output devices. Assistive technologies are particularly useful for visually impaired students who face exceptional difficulties because they do not only have to understand printed script but they also have to interact in learning situations that are fundamentally visual in nature. This is certainly the case in language classrooms.

Despite its rapid growth, inclusive education remains a major challenge for many countries as it requires enormous investments in infrastructure and changes in people's attitudes. One of the most crucial and yet challenging aspects of innovation is implementation. Klein and Sorra (1996) believe that innovation implementation is "the transition period during which [individuals] ideally become increasingly skillful, consistent, and committed in their use of an innovation. Implementation is the critical gateway between the decision to adopt the innovation and the routine use of the innovation" (p. 1057). According to the researchers, there are two important conditions for innovation use, which are a strong climate for innovation implementation and good innovation-values fit (p. 1077). Klein and Knight (2005) argue that "In the absence of effective implementation, the benefits of innovation adoption are likely to be nil" (p. 246). In addition, inclusive education requires dedicated teaching personnel. The teacher should be capable of balancing the needs of disabled and normal students. Therefore, teachers' attitudes, understanding and commitment are instrumental in the success of inclusive programs (Hui, 2015). Teachers' attitudes towards inclusion vary across the education field. AlZyodi (2006) is of an opinion that "teachers' beliefs and acceptance of the policy and philosophy of inclusive education are significant predictors of the degree to which they carry out inclusive practices" (p. 61). According to Al-Zyodi (2006), factors that can potentially influence the opinions of the teachers include "The nature and severity of their students' disabilities, teachers' previous experience with students with disabilities and contextual factors related to the individual schools (p. 61).

\section{Method}

The study reported in this paper sought to examine teachers' views and opinions about successful and challenging aspects of the inclusion of special needs university English language learners in Oman, using assistive technologies in addressing the problems faced by blind and visually impaired students and creating an inclusive language learning environment. In the framework of the study, the concept of language learning environment was understood as the diverse physical locations, 
contexts, and cultures in which students learn (The glossary, 2013) that encompass a wide variety of factors, policies, administrative structures, as well as other features and subjects.

\section{Study context}

In 2008, the Omani government passed a law to protect the rights of people with disabilities (Welfare and rehabilitation, 2008). The law stipulates many rights that people with disabilities enjoy, one of which is the right to free educational services commensurate with their sensory, physical and mental capabilities. Enacting such legislations obviously requires enormous efforts, as well as specific considerations related to designing and implementing learning environments that ensure appropriateness and accessibility for people with physical disabilities (Permvattana, Armstrong \& Murray, 2013). Recently, the Ministry of Education in the Sultanate of Oman started integrating students with mild disabilities into the mainstream basic and post-basic learning environments, thus supporting different and diverse students learning side by side in the same classroom (The value of inclusive education, 2015). As reported in Hussien, Al-Shayeb and Al-Qaryouti (2015), in 2008, the Ministry of Education in Oman set a goal to create inclusive schools, and currently a total of 5,325 individuals with disabilities are receiving services in Oman provided by the Ministry of Education, and the Ministry of Social Development in special education classes in 155 public schools for a total of 1,565 students; 1,262 students with intellectual disabilities and 303 students with hearing impairments.

Higher education institutions in Oman have also followed this suit. Sultan Qaboos University is one of them. The university has started accepting visually impaired students among other students with disabilities and taking practical steps to construct an environment that can be specific for these students, and easily accessible and usable by them. In addition, learning in such environment can facilitate their educational experiences in the context and culture of a tertiary education institution and help them become more inclusive partners in the process of developing their knowledge and skills. The steps have included providing necessary facilities and resources (e.g. special computer laboratories, laptops with refreshable Braille display devices, ebooks, etc.); setting up assistive technologies (e.g. computer access aids, communication software, alternative keyboards, etc.); developing peer-tutoring practice in educational institutions; and encouraging inventions to support effective learning. To exemplify, one of the most recent inventions relates to tactile display apparatus that supports the Arabic language. Entitled Method and System to Convert Portable Document Format to Braille, it has been filed as provisional patent application in the US Patent \& Trademark Office (USPTO) by the university's students of the Electrical and Computer Engineering Department in the College of Engineering (Method and system, 2017). Specific efforts have also been made to support research initiatives and research projects.

The Foundation Program at Sultan Qaboos University is the first and one of the most important stages for providing such a smooth transition from secondary to tertiary education and assisting students' adjustment to the university life. It is aimed at developing literacy, numeracy, computing and learning skills, allowing students a pathway into tertiary education and preparing them for their future academic studies and employability. The foundation program at Sultan Qaboos University was designed in line with the Oman General Foundation Program Standards in the form of learning outcomes for English, mathematics, information technology and study skills. The goal of the English language strand of the foundation program is to prepare students for their active participation in higher education studies and to develop their four main language skills: listening, reading, speaking and writing. The English foundation program is divided into six proficiency levels. The development of these courses and their smooth running demands a lot of effort to meet the needs of the students who were mainly educated in government schools, where the language of instruction for all the courses was Arabic. The majority of the students have limited contact with English in real life situations outside the classroom and therefore rely almost completely on classroom instruction to acquire the language. The English language teachers come from diverse language and cultural backgrounds. Teaching involves traditional and virtual learning environments on a 
Moodle platform with some independent community-based learning where students are given various activities and tasks. These tasks are devised to help Foundation Program students become more inclusive partners in the process of developing their linguistic capabilities, study and generic skills.

Recently, the Foundation Program has started to accept students with disabilities. This commenced with visually impaired students and later spread to other disabilities, mostly physical. This came in line with the university's plans to accept disabled students. Until recently, blind students, who are the focus of this study, have mainly been accepted into humanities majors, as these majors have been deemed to be more suitable for their needs and abilities and less hazardous for them, when compared to majors such as chemistry, biology, mechanical engineering, etc. However, the university conducted a comprehensive survey in 2014 to identify the majors suitable for students with different disabilities. As a result of this, the students now have more options. There have been many cases of blind students outperforming the their peers.

At the Centre for Preparatory Studies, the blind and visually impaired students taking any of the foundation English language courses are placed in the same classroom together with the normal students. The students have access to a number of resources, such as a special computer laboratory, laptops with refreshable Braille display devices, e-books, etc. These students sometimes feel lost, lonely or demotivated as they do not follow the same usual route in learning as their sighted peers. That is, they have to access and comprehend written text and interact in a learning environment that is inherently visual in nature (Al Ghafri, 2015).

\section{Study Design}

The study was designed to take an interpretative approach that relied on linguistic data and employed meaning-based forms of data analysis (Elliott \& Timulak, 2005). Klein and Myers (1999) explain that the interpretative approach is based on an assumption that "our knowledge of reality is gained only through social constructions such as language, consciousness, shared meanings, documents, tools, and other artifacts" (p. 69). In AlRiyami's (2015) view, the use of the interpre- tive approach makes it possible to conduct a study in its natural setting" (p. 413). Walsham (1993) argues that interpretive methods of research start from the position that our knowledge of reality, including the domain of human action, is a social construction by human actors.

The fundamental basis of the study was the setting up and conducting fieldwork. Plummer (2001) points out that in life histories, obtaining relevant information can be accomplished by chance, luck and being pragmatic. Bogdan and Biklen (2003) suggest purposeful sampling. In our study, the data was obtained from specific sampling of language teachers at the Centre for Preparatory Studies at Sultan Qaboos University. Only teachers who had experience of teaching visually impaired students in both foundation and credit-bearing English courses offered by the centre were invited. Such an approach allowed exploring personal histories and experiences in a specific context of tertiary education level language institution.

\section{Data Collection}

Data was collected during a one-year period at the Foundation Program at the Centre for Preparatory Studies (former Language Centre) at Sultan Qaboos University. The study utilized face-to-face qualitative interviews with the English language teachers to obtain information. The participants were asked to give elaborated accounts about their experiences and practices.

A set of open-ended and exploratory questions for teachers' interviews was designed to include Elliott's (2000) five types of exploratory questions, namely definitional, descriptive, interpretative, critical/action, and deconstruction (see Appendix 1 for more information about the interview questions). The developed set of questions helped the researchers stay focused on the interview without imposing too much structure (Elliott \& Timulak, 2005). The participants were provided with the set of questions sent to them by e-mail as recommended by Hill, Thompson and Williams (1997).

The interview questions asked the participants about elaboration and examples, and aimed to draw out what teachers felt about technological and pedagogical support given to visually impaired students for them to meet learning 
outcomes and standards of competency in English, and successfully integrate into the mainstream English language programs. They also focused around the key question: "What challenges they face with creating accessible and usable inclusive language learning environment for visually impaired students?". The researchers tried to give power to the participants and empower them to take the lead and to point out important features of the inclusive language learning environment (Elliott \& Timulak, 2005).

To yield a richer and more balanced picture of inclusive language teaching and learning, the researchers also observed teachers' work with visually impaired students in the learning environments of the computer laboratory and inclusive classroom, and during their office hours in the centre.

\section{Data Analysis}

The data were obtained in the form of notes. As suggested by Elliott and Timulak, (2005), obvious redundancies, unimportant information, and repetitions were omitted, and data were divided into distinctive meaning units with which we did data analysis. Also, sorting data into the units allowed for providing a conceptual framework of the study (Hill et al., 1997). The distinctive units identified such aspects related to the study, as respondents' views about inclusive education, their experiences with assistive technologies, including specific challenges that they have faced, and respondents' views about training and professional development.

\section{Findings and Discussion}

All teachers who participated in the study understood their social and professional responsibility for meeting educational and future employability needs of blind and visually impaired students, and giving an individual character to their teaching approaches to mitigate language and study challenges of these students. Also, all of them had a very positive disposition to teaching visually impaired students in their classrooms. In Zoya's views, "Teaching visually impaired students is challenging but also rewarding". Bella commented that her experience of teaching the visually impaired students at Sultan Qaboos University clearly demonstrated to her "that such students are very receptive to information and use their other, very sharp, senses to understand the information. For example, they listen very carefully and they can describe sensations like taste very well".

Teachers' responses clearly demonstrate their support of inclusive education. This finding is also supported by observations of the participants' work with visually impaired students in the learning environments of the computer laboratory and inclusive classroom, and during their office hours in the Centre for Preparatory Studies. Zoya also shared some useful approaches and techniques that were very helpful and useful. These include, according to Zoya,

(a) assigning students-volunteers from class to help visually impaired peers during class time (e.g. one different student every week);

(b) constantly keeping in touch with the visually-impaired students, student officer and volunteer students who help them outside class and boost motivation, monitor the progress and enable the teacher to offer help whenever needed;

(c) coordinating assessments at times that suit the visually-impaired students;

(d) continuously checking on the visuallyimpaired students during class and whenever there is a chance to help him/her with the course materials dealt with in class;

(d) encouraging classmates to come forward and offer help (e.g. escorting the visually impaired students to the next class which sometimes is in a different block, inviting them to come for a study group, bringing them to class);

(e) other students in class have the opportunity to interact with the visually impaired students which is good for their mental and psychological development";

In Zoya's view, "simple things can make a difference; the visually impaired students will blend with their classmates and feel part of the class. This helps with the class interaction too, visually impaired students' motivation and with their academic achievement." 
Similarly, all participants commented positively in their interview responses and the discussions about assistive technologies. ${ }^{1}$

When asked about her experience of using assistive technologies to support students inclusion into the language learning environment, Bella commented: "Regarding assistive technology, the low vision use their portable magnifiers to look at the board and textbooks. The legally blind use their Braille sense devices to read, take notes, record the lecture and answer questions of activities. I sometimes use the projector so I can enlarge the fonts for the low version."

Helen explained: "The visually impaired students can read more without the bulk of Braille books, and are far more independent". According to Helen, students are very happy when assistive technologies are used in class. She explained: "They have this completely new sense of enthusiasm, and so much more independence. They are no longer dependent on a Human/Peer reader".

The majority of the teachers who participated in the study gave long thoughtful reflections, suggesting that assistive technology is "crucial to language learning as visually impaired students can't read or write unless they use a computer" (Saud) and can be "a great help to enable blind students to take up more courses and not limit their options" (Helen). Mary also commented: "Assistive technology plays a big role in learning. For example, students can have their material as a hard copy. Large font for low vision and Braille for blind. However, low vision for example would still have problems. Using the magnifier, students can take a screen shot either from the board or book then change the background color to suit them, change the font size and save it".

In the participants' view, assistive technology can successfully promote language learning for visually impaired students. For example, Mary noted that, "The visually impaired students can read more without the bulk of Braille books, and are far more independent".

\footnotetext{
${ }^{1}$ According to Mary, "all students at the Centre for Preparatory Studies are provided with the devices that suit their needs such as Braille Sense U2, magnifiers, Super Nova Screen Reader, IRead NowCamera system and Clear View+HD".
}

In Helen's opinion, students became very happy when technologies are used. She commented, for example, that students "have this completely new sense of enthusiasm, and so much more independence. They are no longer dependent on a Human/Peer reader".

Sara explained: "The students feel as though they have now no barriers as such for them to read and learn English as a language to explore new worlds of knowledge". In other words, assistive technology has become a selfmanagement tool for these students (Wiazowski, 2009).

Commenting on assistive technologies in inclusive language classroom, Mary expressed an opinion that assistive technology allows visually impaired students to achieve the highest level of independence. According to her, "Being provided devices, such as Braille Sense, magnifiers, iPads, students are able to equal access of information and to complete tasks efficiently. For example, in class legally blind or visually impaired students won't be able to access information if they haven't been provided with the appropriate devices. Students save the material in the devices if that is their preference. Others prefer hard copies. Moreover, how will they be able to take notes! Or complete a task! What if they have been asked to prepare a presentation? They will need the device to search, take notes and present it".

Interestingly, teachers' responses were all in agreement with the integration of assistive technologies in the inclusive language learning environment. For them, assistive technologies are a positive change in teaching. However, the study revealed that most participants had very limited experience with assistive technologies (e.g. computer access aids including modified keyboards, screen readers, Braille note takers, voice over text software, etc.), and there was very little about exactly how and in what ways they would like to see the assistive technologies to be involved in constructing effective learning environment.

When asked about the specific challenges in teaching visually impaired students, all participants mentioned both technological and pedagogical challenges. In more detail, they reported challenges related to insufficient training in techniques, methods and approaches to teaching visually impaired students, as well as 
the limited number and range of teaching aids and resources developed in-house specifically for vision impaired English language learners. They also noted some challenging aspects related to assistive technologies.

In response to the question about the challenges with assistive technologies, Helen focused on some particularly challenging aspects of assistive technologies' implementation. She commented: "The student actually listens all the time, so the challenge is overburdening their listening and their memory instead of a Braille book that they will touch and re-read, not use hearing/listening". She further went on saying: "We have to realize there are three other senses they can use apart from Sight, which are Touch, Taste and Hearing, but all assistive technology is focusing on Hearing, I believe traditional braille enables use of Tactile sense. I feel listening can and does shut out if their mind wanders, I am also unsure how much accent, voice and pronunciation is a hindrance in Listening. Braille takes away all those hindrances; yes, they are bulky, but I have proof that they are in constant 'touch' of the shape of the spellings, and know that they are actually reading. It also enables them to read aloud! This is a completely new use of the braille copy".

In Mary's view, her biggest challenge was "lack of materials in accessible formats". Francis made a similar comment.

In relation to challenges, Helen commented: "It would have been beneficial to have been told that I would have a visually-impaired student in my class and what things to look out for and how to organize the class and materials to my students' advantage".

Indeed, all participants reported doing work "on best effort basis". Many of them commented on their personal initiatives to learn more about inclusive education, and improve their teaching practice. Helen, for example, remarked on her personal experience as follows: "I didn't get any experience in teaching visually impaired but I have always tried to improve my skills by getting information from experienced people and reading articles on the internet". Saud commented that he had attended a Braille training course run by the university. He had an experience of teaching visually impaired students for two semesters in the context of inclusive language learning environment.

All study participants noted the importance of in-service professional development. For example, according to Helen, she unfortunately "had no training in dealing with this situation", "knew nothing about the technologies", and she "might have dealt with the situation differently", if she had had some. The importance of training in implementing successful inclusive learning environment and formation of positive attitudes towards inclusive education was supported by the findings of a number of studies. These studies, first and foremost, highlight the role of experienced teachers eager "to serve as resource persons, to prepare special materials, as required, and to provide special instruction in those skills peculiar to blindness such as Braille reading and writing, use of reader services, auditory perceptual training and orientation and mobility" (Sanghvi, 2015, p. 560).To illustrate, according to Al-Zayoudi (2006), for inclusive education to become a sustained reality, it requires immense preparations in terms of teacher training, materials, resources, as well as "teachers' beliefs and acceptance of the policy and philosophy of inclusive education" (p. 61).

Indeed, the Centre for Preparatory Studies is still at the initial stage of using assistive technology for learning and teaching. More inservice training and professional development for teachers of visually impaired teachers is needed in general and in assistive technologies. As Permvattana, Armstrong and Murray (2013) contend, "Teachers need to know how to solve learning problems that relate to vision disabilities; they need to understand not only assistive technologies, but also how to work around inaccessible features of the curriculum and the learning environment" (p. 15). Such training is gaining even more importance, especially "In a time when quality of teaching has been found to most influence learner achievement" (Hock, 2015, p. 6).

\section{Conclusion}

Learners with disabilities have the right to equal and quality education. Nowadays, more educational institutions in countries worldwide move towards inclusive education that ensures visually impaired students equal opportunities with their sighted peers "for suc- 
cess in mastery of course material ... without compromising the content, quality or level of instruction" (Optimizing, 2014, p. 3). The inclusive education movement has certainly given these students hope for such opportunities. However, the concept is still developing in many countries, and Oman is not an exception.

The experience of the Centre for Preparatory Studies at Sultan Qaboos University with innovating in language education of visually impaired students clearly demonstrates that Oman's higher education is at the initial stage of designing and implementing effective inclusive learning environments supported by assistive technology. There is evident governmental and institutional support in place. This support includes production of policy documents, legislation, promotion of the use of innovation in teaching and raising awareness, creation of all the necessary infrastructure to achieve success inclusive education, including the purchase of equipment needed to support the idea of assistive technology, as well as establishment of facilities specific for inclusive learning environment. Additionally, it focuses on human resources, namely hiring specialists in assistive technology, provision of materials and expert training. Moreover, there is noticeable support of research ideas, projects, and initiatives intended to increase teachers' awareness about the innovations, and students' enthusiasm and positive response towards inclusive environment supported by the use of assistive technology. Nevertheless, it is important that the Centre for Preparatory Studies, similar to other higher education institutions, should promote social inclusiveness among its student body to make disabled students feel they are welcome, and inclusive education become the collective responsibility of the whole institution.

Technological advances have certainly made it easier for the Centre of Preparatory Studies as an educational institution to respond to the needs of students with disabilities. However, successful integration requires systematic planning, clear policies, procedures, and professional development. Teachers may have the willingness to help disabled students but because they lack the knowledge or skills about how to best to do that their efforts remain constrained. Success for students with disabilities is largely contingent on the support provided.
The challenges that teachers face are compounded given the novelty of the concepts of inclusive education and assistive technology. Teachers must be knowledgeable about the nature and needs of learners with different disabilities to be able to provide them with the support they need. The suggested pathway for future developments in this field should involve enhancement of teachers' knowledge and expertise in inclusive education, systematic planning and material design for inclusion as focus of attention.

\section{Recommendations}

This study recommends that policy makers at higher education institutions address the need in teacher training in using assistive technologies and developing accessible teaching materials and curricula in order to construct learning environment that is beneficial for facilitating learning experience of visually impaired students. As well as that, higher education institutions should take the views of teachers and students with disabilities into consideration in the planning and provision of programs and services, and further promote social inclusiveness among its student body to make the disabled students feel they are welcome.

\section{References}

Ainscow, M. (1999). Understanding the Development of Inclusive Schools. London: Falmer.

Ainscow, M. (2005). Developing inclusive education systems: What are the levers for change? Journal of Educational Change, 6, 109-124. DOI 10.1007/s10833-005-1298-4.

Al Ghafri, M. (2015). The challenges that visually impaired students at Sultan Qaboos University face in learning English. Proceeding of the 3rd Global Summit on Education GSE 2015, 9-10 March 2015, Kuala Lumpur, Malaysia. Retrieved April 6, 2017 From:

http://worldconferences.net/proceedings /gse2015

Al Riyami, T. (2015). Main approaches to educational research. International Journal of Innovation and Research in Educational Sciences. 2(5), 412-416. Retrieved October 28, 2016. From: 
Alirezaeian, V., Chegini, A.S. \& Farjad, Z.N. (2015). A Portrait of Computer-Assisted Language Learning research: History, typology, and normalization. International Journal of English and Education, 4(2), 94104. Retrieved February13, 2017. From: http://www.ijee.org/yahoo_site_admin/ assets/docs/10.86141412.pdf.

Al-Zayoudi, M. (2006). Teachers' attitudes towards inclusive education in Jordanian schools. International Journal of Special Education, 21(2), 55-62. Retrieved June 1, 2017. From:

http:/ / files.eric.ed.gov/fulltext/EJ843606. pdf.

Bogdan, R.C. \& Biklen, S.K. (2003). Qualitative research for education. An introduction to theory and methods. 4th ed. United States of America: Pearson Education Group Inc.

Bowman, I. (1986). Teacher training and the integration of handicapped pupils: Some findings from a fourteen nation UNESCO study. European Journal of Special Needs Education, 1, 29-38.

Dudeney, G. \& Hockly, N. (2012). ICT in ELT: How did we get here and where are we going? ELT Journal, 66(4), 533-542. Retrieved May 23, 2017. From http:/ /dx.doi.org/10.1093/elt/ccs050.

Elliott, R. \& Timulak, L. (2005). Descriptive and interpretive approaches to qualitative research. J. Miles \& P. Gilbert (Eds.). A handbook of research methods for clinical and health psychology, (pp.147-160), Oxford: Oxford University Press.

Elliott, R. (2000). Rigor in psychotherapy research: The search for appropriate methodologies. Unpublished paper, Department of Psychology, University of Toledo.

Evans, J. (2017). Equality, education, and physical education. Routledge Library Editions: Sociology of Education.

Hill, C. E., Thompson, B. J. and Williams, E. N. (1997). A guide to conducting consensual qualitative research. The Counseling Psychologist, 25, 517-572.

Hock, R. (2015). Book review: Hayes, D. (Ed.) (2014). Innovations in the continuing professional development of English language teachers. LC Forum, 12, 6-8. http://www.ijires.org/administrator/co mpo-

nents/com_jresearch/files/publications/I JIRES_361_Final.pdf.

http://www.llcc.edu/wpcontent/uploads/2014/10/OptimizingLearning-Environment-1.pdf.

https://www.mindbank.info/item/5889.

Hui, M. (2015). Factors Influencing the Success of Inclusive Practices in Singaporean Schools: Shadow Teachers' Perspectives. Unpublished master's thesis, University of Oslo.

Hussien, J., Al-Shayeb, A.O. \& Al-Qaryouti, I. (2015). Omani stakeholders' preferences for educational placement of students with disabilities. Journal of Educational and Psychological Studies, 9(4), 628-644. Retrieved May 15, 2017. From: https://www.squ.edu.om/LinkClick.aspx fileticet=QCTFPvysbyQ\%3D\&portalid=53.

Hwang, Y. \& Evans, D. (2011). Attitudes towards inclusion: gaps between belief and practice. International Journal of Special Education, 26(1), pp. 136-146.

Klein, H. K. \& Myers, M. D. (1999). A Set of Principles for Conducting and Evaluating Interpretive Field Studies in Information Systems. MIS Quarterly. 23(1), 67-94.

Klein, K. J., \& Knight, A. P. (2005). Innovation implementation: Overcoming the challenge. Current Directions in Psychological Science, 14(5), 243-246.

Klein, K.J., \& Sorra, J.S. (1996). The challenge of innovation implementation. Academy of Management Review, 21, 1055-1080.

Lindsay, G. (2007). Educational psychology and the effectiveness of inclusive education/mainstreaming. British Journal of Educational Psychology, 77(1), 1-24.

Manset, G. \& Semmel, M.I. (2016). Are inclusive programs for students with mild disabilities effective? A comparative review of model programs. The Journal of Special Education, 31(2), 155 - 180.

Meijer, C. J. W. (2010). Special needs education in Europe: Inclusive policies and practices. Zeitschrift für Inklusion. Retrieved on June 19, 2017. From: http://www.inklusion- 
online.net/index.php/inklusiononline/article/view/136/136

Meriam Webster Dictionary (2017). Innovation. Retrieved May 27, 2017. From: https://www.merriamwebster.com/dictionary/innovation.

Method and system to convert portable document format to Braille. (2017). SQU website. Retrieved May 31, 2017 from https://www.squ.edu.om/squresearch/ News-Studies/SQU-2nd-Patent.

Milrood, R. (2004). Training Teachers as Managers of Innovative Projects: from indifference to power. Tambov: Tambov Pedagogical University Printing Press.

Optimizing the learning environment for students with disabilities (2014). Retrieved May 1, 2017. From:

Permvattana, R., Armstrong, H. \& Murray, I. (2013). E-learning for the vision impaired: A holistic perspective. International Journal of Cyber Society and Education, 6(1), 15-30, 2013. Retrieved April 21, 2017. From: http://www.academicjournals.org/ojs2/i ndex.php/IJCSE/article/viewFile/1029/1 36.

Plummer, K. (2001). Documents of life 2. An invitation to a critical humanism. London: Sage Publications Ltd.

Rafferty, Y., Boettcher, C. \& Griffin, K. (2001). Benefits and risks of reverse inclusion for preschoolers with and without disabilities: Parents' perspectives. Journal of Early Intervention, 24(4), 266-286.

Sanghvi, A. (2015). Effective use of online resources for provision of reading materials to ensure participation, critical thinking development and fair and full inclusion of visually impaired students in the mainstream university classroom, Y. Ono (Ed.), 59th Yearbook of Teacher Education (pp.557576). Naruto University of Education, Naruto: Japan. Retrieved May 23, 2017. From:

http://www.icet4u.org/docs/Naruto_20 15.pdf.

Sharma, U., Loreman, T., \& Forlin, C. (2012). Measuring teacher efficacy to implement inclusive practices. Journal of Research in Special Educational Needs, 12(1), 12-21.
Snyder, R. (1999). Inclusion: A qualitative study of in-service general education teachers' attitudes and concerns. Education, 120(1), 173-181.

The best definition of innovation (2016). Scott Berkun website. Retrieved May 27, 2017. From: http://scottberkun.com/2013/thebest-definition-of-innovation/.

The glossary of education reform. (2013). Retrieved May 1, 2017. From: http://edglossary.org/learningenvironment/.

The value of inclusive education. (2015). Open society foundations website. Retrieved April 24, 2017. From: https://www.opensocietyfoundations.org /explainers/value-inclusive-education.

Torreno, S. (2012). The history of inclusion: Educating students with disabilities. Bright Hub Education. Retrieved on June 15, 2017 from:

http://www.brighthubeducation.com/sp ecial-ed-inclusion-strategies /66803-brieflegal-history-of-inclusion-in-specialeducation/.

Tuzlukova, V. (2009). Challenges and opportunities of using regional English language materials. Paper presented at the 5th VTTN National ELT Conference, Learning English in a Changing World. 16 - 17 January, 2009, Hanoi, Vietnam.

U.S. Department of Health and Human Services Administration on Aging. Fact Sheet. (2003). Retrieved on June 15, 2017. From: http://gero.usc.edu/nrcshhm/resources/ fs_assitive_tech.pdf.

Walsham, G. (1993). Interpreting information systems in organizations. Chichester: Wiley.

Welfare and rehabilitation of persons with disabilities act. (2008). Retrieved May 1, 2017. From:

Wiazowski, J. (2009). Assistive technology for students who are blind or have low vision. J. Gierach (Ed.). Assessing Students' Needs for Assistive Technology. (pp.1-30). Wisconsin, USA. Retrieved June 1, 2017. From: http://www.wati.org/content/supports/ free/pdf/Ch12-Vision.pdf. 


\section{Appendix 1: Interview questions}

1. What is your teaching experience?

2. What is your teaching experience in Oman?

3. What is your teaching experience related to teaching visually impaired students?

4. Have you ever had training/ professional experience related to teaching visually impaired students and integrating assistive technologies in teaching visually impaired students?

5. Have you ever tried to integrate assistive technologies in teaching visually impaired students?

6. What are the biggest challenges in teaching visually impaired students, e.g. lack of materials; lack of training; lack of assistive technologies, etc.?

7. Can assistive technologies enhance the visually impaired students' language learning? If yes, in what way?

8. Have you ever used assistive learning technologies in teaching? If yes, what exactly have you used? (e.g. computer access aids include light pointers, modified or alternate keyboards, voice to text software, switches activated by pressure/sound/voice, touch screens, special software and head sticks; and environmental control systems help people control various appliances such as switches for appliances like the telephone/TV, and are activated by pressure, eyebrows or breath, etc.).

9. How do the assistive learning technologies promote successful learning of visually impaired students?

10. What aspects of the assistive learning technologies' implementation were particularly challenging?

11. How did the students react to the assistive learning technologies?

12. How did the assistive learning technologies change/affect your views towards inclusive education?

13. Can you describe how you have used the assistive learning technologies in aiding teaching/learning?

14. How can the assistive learning technologies be changed/improved to facilitate learning and inclusion?

15. To what extent are you trained to use the assistive learning technologies effectively?

16. What support do the visually impaired students receive in using the assistive learning technologies? 